\title{
مشاكل التوجيه والإرشاد وجهود التحسين الإسلامي في قسم التربية اللغة العربية
}

\author{
سيف الانام \\ في جامعة العلوم التربوية المدنية (STITMA) يو كياكرتا \\ Anams9763@gmail.com
}

\section{ملخص}

المشاكل الداخلية هي المشكلات التي تنشأ من داخل الطلاب أو العوامل ملحصل

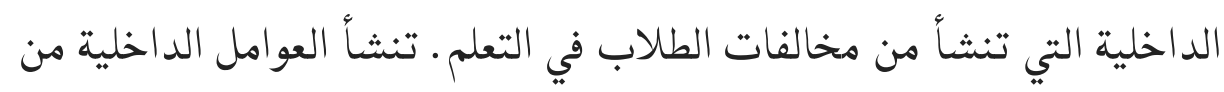
داخل الطالب نفسه، مثل : الصحة، الأمن، عوامل القدرة الفكرية، العوامل المؤثرة مثل الشعور والثقة، الدافع، النضج للتعلم، العمر والجنس، الخلفية الاجتماعية، عادات الدراسة، القدرة على التذكر والإحساس بالقدرات مثل :

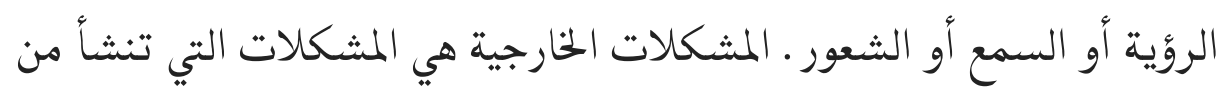
خارج الطالب أو العوامل الخارجية التي تسبب المخالفات لدى الطلاب في التعلم. العوامل الخارجية هي العوامل التي تأتي من خارج الطلاب، مثل : نظافة المنزل ، والهواء الساخن ، وغرف الدراسة التي لا تفي بالمتطلبات، وعدم كفاية أدوات التعلم، والبيئة الاجتماعية والطبيعية، وجودة عملية التعليم والتعلم. التوجيه والمشورة التي تنطوي على هذه المؤسسة المشورة، بطبيعة الحال لا يكن

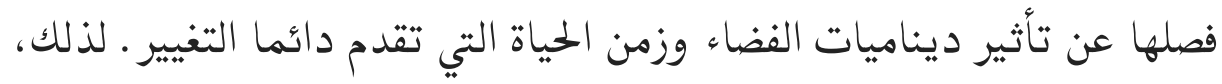

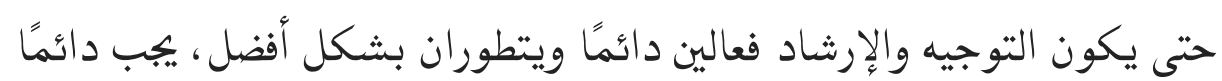


سيف الانام : مشاكل التوجيه والإرشاد وجهود التحسين الإسلامي في قسم التربية اللغة العربية

تطبيق المشكلات والحلول البديلة الموجودة في الإرشاد ـ الإرشاد والمشورة مهمة لجميع العناصر المشاركة في عالم التعليم، بما في ذلك الطلاب أو آولياء الأمور أنفسهم . النصائح والمدخلات والتوبيخ هي الأثياء التي يجب القيام بها في كل انتهاك للطالب. بالإضافة إلى ذلك، يتم دائمًا غناء صلوات الآباء والمعلمين وصلوات العاملين في الاستمالة الآخرين، لذلك يسعد الله أن يعطي لئي إرشاد اته ويصبح الطلاب أشخاصًا شخصيًا .

الكلمات المفتاحية : مشاكل التوجيه والإرشاد ، الجهود المبذولة لتحسين الإسلام

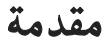

أصل الكلمة، عبارة التوجيه هي ترجمة لكلمة "التوجيه" التي تأتي من

الفعل "إلى الدليل"، مما يعني "إظهار" أو "توجيه" أو "توجيه" أو "مساعدة" . وققا للمصطلح، ثم بشكل عام، يمكن تفسير الإرشاد على أنه مساعدة أو إرشاد . على الرغم من المصطلحات، يعرف وينكل التوجيه : أولاً ، الجهود المبذولة لتزويد الأفراد بالمعرفة والحبرة والمعلومات حول أنفسهم . ثانياً، طرق تقديم المساعدة للأفراد لفهم جميع الفرص المتاحة لهم من أجل التنمية الثخصية بكفاءة وفعالية. ثالثًا ، نوع من الخدمة للأفراد حتى يتمكنوا من اتخاذ الخيارات وتحديد الأهداف بشكل صحيح ووضع خطط واقعية حتى يتمكنوا من التكيف لإرضاء أنفسهم في البيئة التي يعيشون فيها ـ رابعا ، عملية تقديم المساعدة أو المساعدة

8 Jamal Makmura Asmani, Panduan Efektif Bimbingan dan Konseling di Sekolah, (Jakarta: Diva Press, 2010), hlm 31

\section{IHTIMAM}


للأفراد من حيث فهم أنفسهم، وربط فهم أنفسهم بالبيئة، واختيار وتحديد وتخطيط وفقا لمفاهيمهم ومتطلبات البيئة الخاصة بهم." مشاكل مختلفة - المثكلات في المدرسة، وخاصة في الطلاب أنفسهم والتي لا يمكن حلها عن طريق التدريس من قبل المعلمين العاديين في المدرسة، لحل المشكلات لكل طالب في المدرسة هي إرشادات وإرشادات ضرورية للغاية، ولكن قبل ذلك يكن إجراء الإرشاد والإرشاد بشكل جيد ، أحد المتطلبات الضرورية والمطلقة هو الفهم الصحيح للتوجيه والإرشاد من قبل جميع العاملين في الجامعة المثاركين في أنشطة خدمات التوجيه والإرشاد . يتضمن تنظيم التوجيه والإرشاد في الجامعات جهودًا لتسهيل الطلاب، المشار إليهم فيما يلي باسم الإرشاد ، لتكون قادرًا على تطوير إمكاناتهم أو تحقيق مهامهم التنموية (فيما يتعلق بالجوانب البدنية والعاطفية والفكرية والاجتماعية والأخلاقية والروحية)، وأصبحت حتمية عند مواجهة المثاكل التي تلون عملية التنفيذ التي تنطوي على أثياء كثيرة. ومع ذلك، في هذه الحالة فقط المثكلات أو المشكلات التي سيتم مناقثتها : المؤسسات او التوجيه والمشورة نفسها، الطلاب (المستثارون) والمستثارون .

${ }^{9}$ Winkel. Psikologi Pengajaran. (Jakarta : Gramedia, 2005). hlm. 27

10 W.S. Winkel \& S. Hastuti. Bimbingan dan Konseling di Institut Pendidikan, (Jakarta : Gramedia, 2007), hlm. 3 
سيف الانام : مشاكل التوجيه والإرشاد وجهود التحسين الإسلامي في قسم التربية اللغة العربية

\section{فهم مشكلات التوجيه والإرشاد مصطلح المشكلة / الإشكالية}

ينشأ من اللغة الإنجليزية، وهي "إثكالية" والتي تعني مشكلة أو

مشكلة. بينما في الإندونيسية، فإن المشكلة تعني الأثياء التي لا يكن حلها ؛ الذي يسبب المشاكل. '" التوجيه والإرشاد هي عملية المساعدة أو المساعدة التي يقدمها مستشار للأفراد (المحامون) من خلال اجتماعات وجهاً لوجه أو العلاقات المتبادلة بين الاثنين، بحيث يكون للمشرف القدرة أو القدرة على رؤية المشكلة وإيجاد حل لها ويكون قادرًا على حل مشكلاته ـ لذلك، يكن تفسير مشكلة التوجيه والإرثاد على أنها مشكلة تواجهها في عملية المساعدة أو المساعدة التي يقدمها المستشار للفرد الذي يتم توجيهه. 'r

\section{أنواع المشاكل في الإرشاد على مستوى الجامعة}

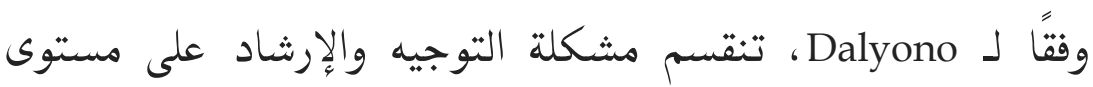

$$
\text { الجامعة إلى قسمين " ' ، هما : المشاكل الداخلية }
$$

المشاكل الداخلية هي المشاكل التي تنشاً من داخل الطلاب أو

العوامل الداخلية التي تؤدي إلى مخالفات الطلاب في التعلم. ' تنشاً 2002), hlm 276)

12 Tohirin, Bimbingan dan Konseling di Sekolah dan Madrasah, (Jakarta: PT. Raja Grafindo, 2007), hlm 57

${ }^{13}$ Dalyono. Psikologi Pendidikan (Jakarta: Rineka Cipta, 1997), hlm. 239

\section{IHTIMAM}




$$
\text { سيف الانام : مشاكل التوجيه والإرشاد وجهود التحسين الإسلامي في قسم التربية اللغة العربية }
$$

العوامل الداخلية من داخل الطفل نفسه ، مثل :أ . الصحة, ب. الشعور بالأمن, ج. عوامل القدرة الفكرية, د ـ العوامل المؤثرة مثل المثاعر والثقة, ه. حافز, و. النضج للدراسة, ز. عمر, ح. النضج للدراسة, ط. عمر, ي. جنس, ك. الخلفية الاجتماعية, ل . عادات الدراسة, م ـ القدرة على تذكر, ن . واستثعار القدرات مثل : الرؤية ، السمع أو الثعور • أ أن مشاكل التعلم الداخلية يكن أن تكون : البيولوجية والنفسية, تعني : المشكلات البيولوجية أنها تنطوي على مشاكل جسدية بطبيعتها ، مثل الصحة والإعاقة ونقص الغذاء وما إلى ذلك. في حين أن الأمور النفسية هي مشاكل نفسية مثل الاهتمام والفائدة والذكاء والكوكبة النفسية التي تظهر العواطف والاضطرابات النفسية.

أمثلة على مشاكل التعلم الخارجي يمكن رؤيتها في الحالات التالية : هalita فصله الذين لم يتمكنوا من القراءة بطلاقة. كل درس قراءة ، يخاف ،لأنه في كل مرة يفتح فمه ، ضحك عليه أصدقاؤه ـ المعلم فقط دعه يذهب وتحويل بدوره إلى طلاب آخرين. نتيجة لذلك ، تتخلف Talita دائمًا عن أصدقائها . في المنزل ، كانت تاليا تُبْ دائمًا لأنها هزمت من قِبل شقيقتها دوللي التي جلست في

14 Sumadi Suryabrata, Psikologi Pendidikan (Jakarta:PT. Raja Grafindo,1998 ), hlm. 233

15 C.G. Boeree, Personality Theories: Melacak Kepribadian Anda Bersama Psikolog Dunia, (Surabaya, Alih Bahasa, 2007). hlm 48 
الفصل الثاني • في هذه الحالة ، يبدو أن هناك تركيزًا أكبر على التأثيرات البيئية ، ويبدو أن تأخر تاليتا في القراءة ناجم عن "الحوف" والإجهاد الناجم عن

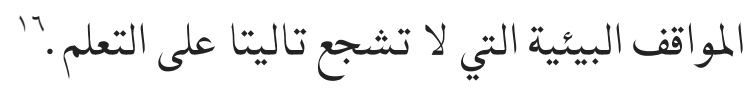

مشاكل في التوجيه الإرشادي التي تحدث على مستوى المدرسة والجهود المبذولة لحل المثاكل في التوجيه الإرشادي نحو التوجيه المثالي المشورة ا ـ المثاكل الداخلية أ. تتركز الإرشادات والمشورة على القضايا السطحية : ( ) الخلفية (1)

بشكل عام، تبداً الجهود المبذولة لتقديم المساعدة برؤية

الأعراض والثكاوى الأولية التي ينقلها العميل. ومع ذلك، إذا

استمرت مناقشة المثكلة واستكثافها وتطويرها ، فغالبًا ما يتبين

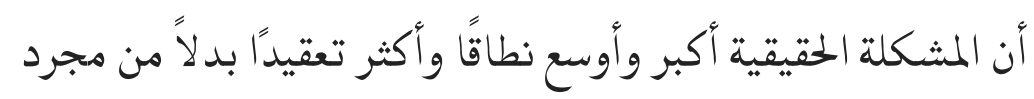
ما يتم رؤيته أو نقله . لمشاكل السطح التي تنشاً فقط. r

يجب أن تركز شركات الحدمات على المثكلة الحقيقية. قد لا يتم إصلاح المستشار بواسطة الثكوى أو المشكلة التي ينقلها

16 Tim Musyawarah Guru Pembimbing. Modul Bimbingan Konseling SMA Kelas XII, (Jakarta: Tunas Melati, 2006). hlm 17 
العميل أولاً . يجب أن يكون المستشار قادرًا على فهم المشكلة

الحقيقية وتحديد المثكلة أو تحديد مشكلة العميل في الواقع.

الإسلام يعلمنا أن نكون ملتزمين بالمثشاكل. كما أثار رسول الله

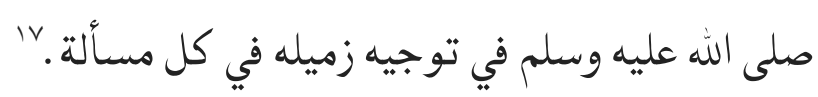

ب.لم يستطع قسم التوجيه والإرشاد تطوير مهنتهم كمستشارين

$$
\text { للمدرسة }
$$

: ( ) الخلفية ()

لا يزال هناك العديد من الطلاب الذين لم يتمكنوا من

تطوير الإمكانات الموجودة داخلهم والتطبيق الأقصى لقسم

التوجيه والإرشاد في المدارس في كل من خدمات التوجيه وعندما

يظهر المحامي القدرة المنخفضة لمستشاري التوجيه والإرشاد في

$$
\begin{aligned}
& \text { الجامعة المعة } \\
& \text { r) جهود التحسين الإسلامي: }
\end{aligned}
$$

للتغلب على هذا في محاولة لزيادة الكفاءة المهنية لمعلمي

التوجيه والإرشاد ، بالطبع ، يمكن القيام بذلك من خلال حضور

الندوات وورش العمل التي تزيد من المعرفة حول الاستثارة

17 Ahmad Muhaimin Azzet, Bimbingan dan Konseling di Sekolah, (Yogyakarta: Arruz Media, 2011), hlm 11 
وغيرها من الأنثطة المتعلقة بالإرشاد .`^يشجع الإسلام الأمة على يُ مواصلة تحسين المعرفة وتطبيق العلم.' المدرجة في هذه الحالة هو

$$
\begin{aligned}
& \text { التوجيه المشورة . } \\
& \text { ج • قيود الوقت في تقديم خدمات التوجيه والإرشاد }
\end{aligned}
$$$$
\text { : ( ) الخلفية }
$$

يتم التغلب على نسبة معلم خدمات التوجيه والإرثاد مع

الطلاب بحوالي 1 : . 10 ، لذلك إذا كان هناك مستشاران فقط في

المدرسة ، فهذا يعني أنهم قادرون فقط على التعامل مع حوالي . ب

طالب بينما تحتوي مدرسة واحدة في بعض الأحيان على . 1.

طالب. عندما يكون موضوع التوجيه والإرشاد من هذه المسألة

يكفي لمقارنة نسبة وعدد المستشارين بما يكفي لتنفيذ التوجيه

$$
\text { والمشورة؛ بالطبع ، سوف نجيب "لا" . }
$$$$
\text { r ( جهود التحسين الإسلامي: }
$$

في هذه المشكلة، يمكن بذل الجهود في هذا الشأن ، حيث

يكن للمستشار إجراء التوجيه الجماعي حتى يتمكن المستشار من

مساعدة المستثشار في إيجاد حلول خاصة به واتخاذ القرارات، بحيث

18 Prayitno dan Erman Emti, Dasar-dasar Bimbingan dan Konseling, (Jakarta: Rieneka Cipta, 2009), hlm. 218 hlm. 7

${ }^{19}$ Imam An-Nawawi. Matan hadist Arbain, (Solo: Insan kamil,2013), 
يكن الاستفادة من وقت قصير للغاية على النحو الأمثل وعلى النحو الأمثل. الإسلام يدعو إلى سهولة الشؤون . بحيث يكن مساعدة أداءالتوجيه والإرشاد من خلال التوجيه الجماعي، أي في الفصل أو

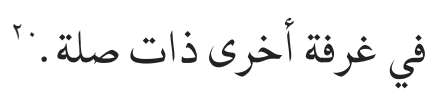

الحلاصة

من شرح المادة المذكورة أعلاه ، يمكن أن نستنتج أن التوجيه والمشورة التي تنطوي على هذه المؤسسة المشورة، بطبيعة الحال، لا يمكن فصلها عن تأثير ديناميات الفضاء ووقت الحياة الذي يوفر دائما التغيير . لذلك، حتى يكون التوجيه والإرشاد فعالين دائمًا ويتطوران بشكل أفضل، يجب دائمًا تطبيق المشكلات والحلول البديلة الموجودة في الإرشاد . يهدف هذا إلى تقليل سوء فهم المعنى الذي سيكون له بالطبع تأثير على الممارسة. العديد من المشاكل التي تحدث في تقديم المشورة، ولدت معظم مشاكل المستشار من فهم عميق لتقديم المشورة ـ لذلك، يجب إعادة بناء صورة العناصر الثلاثة للإرشاد بالكامل لتصبح مؤسسة مريحة حقًا لمشاركة مجموعة متنوعة من المشكلات التي يواجهها الطلاب. العناصر الثلاثة أعلاه ليست أثبياء تعمل بشكل فردي، ولكنها مترابطة فيما بينها ـ لذلك، يجب فهم كل شي؛ ككل حتى يكون التنفيذ هو

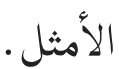

${ }^{20}$ Prayitno. Loc.Cit. hlm. 197-215 
سيف الانام : مشاكل التوجيه والإرشاد وجهود التحسين الإسلامي في قسم التربية اللغة العربية

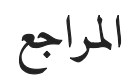

Asmani, Jamal Makmura, Panduan Efektif Bimbingan dan Konseling di Sekolah, (Jakarta: Diva Press, 2010)

Azzet, Ahmad Muhaimin, Bimbingan dan Konseling di Sekolah, (Yogyakarta: Arruz Media, 2011)

Boeree, C.G., Personality Theories: Melacak Kepribadian Anda Bersama Psikolog Dunia, (Surabaya, Alih Bahasa, 2007)

Dalyono. Psikologi Pendidikan (Jakarta: Rineka Cipta, 1997)

Debdikbud, Kamus Besar Bahasa ndonesia (Jakarta, Balai: Pustaka, 2002)

Imam An-Nawawi, Matan hadist Arbain, (Solo: Insan kamil, 2013),

Irvansyah, Relevansi enan nasehat menuntut ilmu dalam pendidikan perspektif Imam Syafi'I dalam kitab Diwan. (Palangkaraya: IAIN, 2017).

Prayitno, Dasar-Dasar Bimbingan dan Konseling, (Jakarta, PT. Rineka Cipta, 2004)

Prayitno dan Erman Emti, Dasar-dasar Bimbingan dan Konseling, (Jakarta: Rieneka Cipta, 2009)

Sumadi Suryabrata, Psikologi Pendidikan (Jakarta:PT. Raja Grafindo,1998 )

Tim Musyawarah Guru Pembimbing. Modul Bimbingan Konseling SMA Kelas XII, (Jakarta: Tunas Melati, 2006)

Tohirin, Bimbingan dan Konseling di Sekolah dan Madrasah, (Jakarta: PT. Raja Grafindo, 2007).

Winkel, W.S Psikologi Pengajaran. (Jakarta : Gramedia, 2005)

Winkel,. \& S. Hastuti. Bimbingan dan Konseling di Institut Pendidikan, (Jakarta : Gramedia, 2007). 